that when concentrations of luteinising hormone are high throughout the follicular phase, as in some women with polycystic ovaries, the hormone penetrates the follicle and allows the oocyte to mature prematurely, resulting in ovulation of an oocyte that is physiologically "aged." Such oocytes are unlikely to be fertilised or will tend to produce embryos that implant poorly and therefore abort. Data that support this model were reported in studies of pigs in which premature ovulation (and presumably maturation of oocytes) was induced with human chorionic gonadotrophin $^{10}$ and in studies of rats in which insemination was delayed. ${ }^{11}$ In both studies the interval between maturation of the oocytes and fertilisation was extended and rates of fertilisation and embryo survival were impaired. In women extension of the interval between ovulation and insemination was associated with a striking increase in the rate of miscarriage. ${ }^{12}$ Moreover, Stanger and Yovitch, Howles et al, and Punnonen $e t$ al have reported that high concentrations of luteinising hormone in the few days before oocytes were collected from women for in vitro fertilisation were associated with impaired rates of fertilisation and conception. ${ }^{13-15}$

Our results show that high concentrations of luteinising hormone during the follicular phase, found in many women with the polycystic ovary syndrome, have a deleterious effect on the success of induction of ovulation and conception and may be a causal factor in early pregnancy loss. As recent studies suggest that the polycystic ovary syndrome is common, both in patients attending infertility clinics and in the general population, ${ }^{16} 17$ many patients may perhaps experience early miscarriage because of an endocrine disturbance. A potential treatment for these patients is to induce ovulation with exogenous gonadotrophins after desensitisation of the pituitary with a superactive analogue of luteinising hormone releasing hormone. ${ }^{7}$

1 Armar NA, Adams J, Jacobs HS. Induction of ovulation with gonadotrophin releasing hormone. In: Bonnar J, ed. Recent advances in obstetrics and Emacolog. Vol 15. Edinburgh and London: Churchill Livingstone, gynaecology.

2 McArthur JW, Ingersoll FM, Worcester J. The urinary excretion of interstitial cell and follicle stimulating hormone activity by women with diseases of the reproductive system. $\mathcal{F}$ Clin Endocrinol Metab 1958;18:1202-15.

3 Abdulwahid NA, Adams J, Van der Spuy ZM, Jacobs HS. Gonadotrophin control of follicular development. Clin Endocrinol (Oxf) 1985;23:613-26.

4 Eshel A, Abdulwahid NA, Armar NA, Adams J, Jacobs HS. Pulsatile luteinising hormone releasing hormone therapy in women with polycystic ovary syndrome. Ferril Steril 1988;49:956-60.

5 Adams J, Franks S, Polson DW, et al. Multifollicular ovaries: clinical and endocrine features and response to pulsatile gonadotrophin releasing hormone. Lancet 1985;ii:1375-8.

6 Mason P, Adams J, Morris DV, et al. Induction of ovulation with pulsatile luteinising hormone releasing hormone. $\mathrm{Br}$ Med $\mathrm{f}$ 1984;288:181-5.

7 Jacobs HS, Porter RN, Eshel A, Craft I. Profertility uses of LHRH analogues. In: Vickery BH, Nestor JJ Jr, eds. LHRH and its analogues: contraceptive and therapeutic applications. Part 2. Lancaster: MTP Press, 1987:303-22.

8 Tsafriri A, Pomerantz SH. Oocyte maturation inhibitor. Clin Endocrinol Metab 1986;15:157-70.

9 Dekel N. Hormonal control of ovulation. In: Litwack G, ed. Biochemical actions of hormones. Vol 13. Orlando, Florida: Academic Press, 1986:57-90.

10 Hunter RHF, Cook B, Baker TG. Dissociation of response to injected gonadotrophin between the Graafian follicle and oocyte in pigs. Nature 1976;260:156-8.

11 Austin CR. The egg. In: Austin CR, Short RE, eds. Reproduction in mammals, Part 1. Germ cells and fertilisation. 2nd ed. Cambridge: Cambridge University Press, 1982:58.

12 Guerrero RJ, Rojas OI. Spontaneous abortion and ageing of human ova and spermatozoa. N Engl f Med 1975;293:573-5.

13 Stanger JD, Yovitch JL. Reduced in vitro fertilisation of human oocytes from patients with raised basal luteinising hormone levels during the follicular phase. Br 7 Obstet Gynaecol 1985;92:385-90.

14 Howles CM, MacNamee MC, Edwards RG, Goswamy R, Steptoe PC. Effect of high tonic levels of luteinising hormone on outcome of in vitro fetilisation. Lancet 1986;ii:521-3.

15 Punnonen R, Heinonen PK, Ashorn R, Kujansuu E, Vilja P, Tuohimaa P. Spontaneous luteinizing hormone surge and cleavage of in vitro fertilized embryos. Fertil Steril 1988;49:479-82.

16 Adams J, Polson DW, Franks S. Prevalence of polycystic ovaries in women with anovulation and idiopathic hirsutism. Br Med f 1986;293:355-9.

17 Polson DW, Adams J, Wadsworth J, Franks S. Polycystic ovaries - a commo finding in normal women. Lancet 1988; i:870-2.

(Accepted 9 fune 1988)

\section{Absence of end diastolic frequencies in umbilical artery: a sign of fetal hypoxia and acidosis}

\author{
K H Nicolaides, C M Bilardo, P W Soothill, \\ S Campbell
}

Harris Birthright Research Centre for Fetal Medicine, King's College School of Medicine and Dentistry, London SE5 8RX

K H Nicolaides, MRCOG, senior lecturer

C M Bilardo, MD, research

fellow

P W Soothill, MB, research

fellow

S Campbell, FRCOG, professor

Correspondence to: $\mathrm{Dr}$ Nicolaides.
One of the main challenges of antenatal management is distinguishing between normal small fetuses and growth retarded fetuses, which are at increased risk of intrauterine death or asphyxia at birth. Cordocentesis and analysis of fetal blood gases have shown that some fetuses that are small for gestational age are chronically hypoxic and acidotic. ${ }^{12}$ Cordocentesis, however, is an invasive procedure and not widely available. In hypoxic fetuses the blood velocity in the aorta is decreased. ${ }^{3}$ Doppler measurement of blood velocity is non-invasive but requires expensive pulsed Doppler equipment and an experienced operator. The presence or absence of end diastolic frequencies in the umbilical artery can be ascertained with continuous wave Doppler equipment, which is much cheaper and requires less training of the operator. We examined the relation of the oxygen tension and $\mathrm{pH}$ in fetal blood with the absence of end diastolic frequencies in flow velocity waveforms of the umbilical artery.

\section{Methods and results}

We studied the fetuses of 59 healthy pregnant women who had been referred from other units for investigation of fetal growth retardation. The fetuses were of 21-36 weeks' gestation and had an abdominal circumference below the fifth centile of our normal range. Blood flow velocity waveforms for the umbilical artery were obtained with continuous wave Doppler ultrasound and analysed by a spectrum analyser (Doptek Spectrascan analyser 9000, Doptek, Chichester). A $100 \mathrm{~Hz}$ filter was used to eliminate the low frequencies obtained from movements of the arterial wall. With the mother semirecumbent and the fetus apnoeic, the Doppler probe was moved over the uterus until the umbilical cord waveform was identified
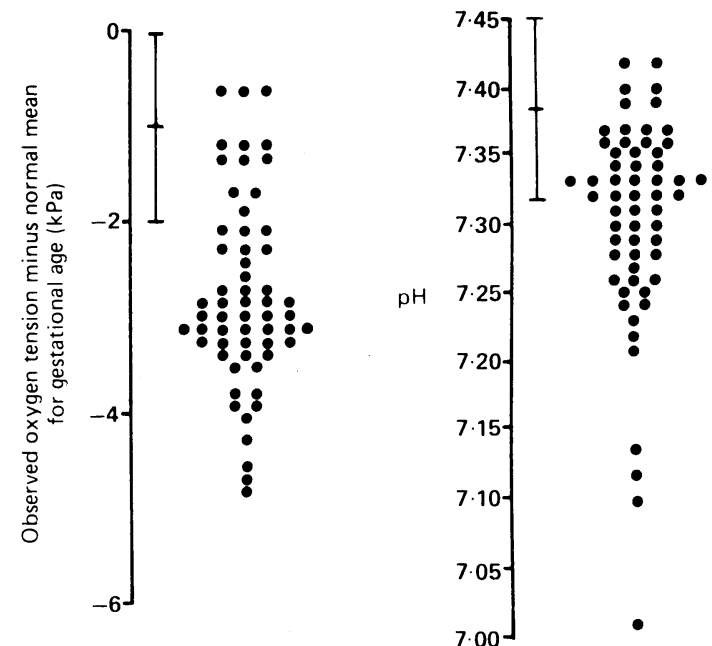

Severity of hypoxia and acidosis in 59 fetuses that were small for gestational age and in which end diastolic frequencies of blood flow in the umbilical artery were absent on continuous wave Doppler ultrasound scanning. Vertical bars show normal range (2SD either side of mean) 
by its characteristic pattern of pulsatile arterial flow and constant venous flow. The waveforms were defined as abnormal if shifts in frequency at the end of diastole were absent in recordings obtained from three different points on the maternal abdomen. A sample of fetal blood was taken from the umbilical vein by cordocentesis, and the oxygen tension and $\mathrm{pH}$ were determined (figure).

The degree of fetal smallness was expressed as the number of standard deviations by which the observed abdominal circumference differed from the normal mean for gestational age, and the severity of hypoxia was expressed as the difference between the oxygen tension observed and the normal mean for gestational age. ${ }^{4}$ The correlation between the degree of fetal smallness and the $\mathrm{pH}$ of blood from the umbilical vein $(\mathrm{r}=-0.095)$ or the severity of fetal hypoxia $(r=-0.02)$ was not significant. Seven fetuses had normal oxygen tensions and $\mathrm{pH}, 25$ were hypoxic, five were acidotic, and 22 were both acidotic and hypoxic.

\section{Comment}

Increased impedance to blood flow in the umbilical artery, as shown by the absence of frequencies at the end of diastole, seems to be a good marker of fetal asphyxia. As all the patients in this study had been referred, and therefore preselected, we cannot comment on the prevalence of this marker in fetuses that are small for gestational age.

The absence of significant correlation between the degree of smallness of the fetus and hypoxia or acidosis shows that uteroplacental insufficiency is not the only cause of small fetal size. Moreover, many babies that are growth retarded because of uteroplacental insufficiency have birth weights that are within the normal range for gestational age..$^{5}$ If waveforms of flow velocity in the umbilical artery prove to be as useful a marker of prenatal asphyxia in well grown fetuses as they are in small fetuses they may replace measurement of fetal size for the antenatal prediction of fetal asphyxia. Missed diagnoses of fetal hypoxia might account for some "unexplained" stillbirths.

1 Nicolaides $\mathrm{KH}$, Soothill PW, Rodeck CH, Campbell S. Ultrasound-guided sampling of umbilical cord and placental blood to assess fetal wellbeing. L ancet 1986;i:1065-7.

2 Soothill PW, Nicolaides KH, Campbell S. Prenatal asphyxia, hyperlactaemia and erythroblastosis in growth retarded fetuses. Br Med f 1987;294:1051-3.

3 Soothill PW, Nicolaides KH, Bilardo CM, Campbell S. Relation of fetal hypoxia in growth retardation to mean blood velocity in the fetal aorta. Lance 1986;ii:1118-9.

4 Soothill PW, Nicolaides KH, Rodeck CH, Campbell S. The effect of gestational age on blood gas and acid-base values in human pregnancy. Fetal Therapy 1986;1:166-73.

5 Chard T. Normality and abnormality. In: Klopper A, Chard T, eds. Plasma hormone assays in evaluation of fetal wellbeing. Berlin: Springer, 1979:1-21.

(Accepted 18 March 1988)

\section{Recurrent early miscarriage and polycystic ovaries}

\author{
M Sagle, K Bishop, N Ridley, F M Alexander, \\ M Michel, R C Bonney, R W Beard, S Franks
}

Departments of Obstetrics and Gynaecology and Chemical Pathology, St Mary's Hospital Medical School, London W2 IPG M Sagle, FRCs(c), clinical research fellow

$\mathrm{K}$ Bishop, medical student N Ridley, medical student F M Alexander, medical student

$M$ Michel, MRCOG, registrar R C Bonney, PHD, research scientist

R W Beard, FRCOG, professor of obstetrics and gynaecology

S Franks, FRCP, senior lecturer in reproductive endocrinology

\section{Correspondence to:}

Dr S Franks, Department of Obstetrics and Gynaecology.
The aetiology of recurrent miscarriages (three or more consecutive spontaneous abortions) is poorly understood. A recent trial suggested that the cause may be immunological,' but the polycystic ovary syndrome may also have a role. Spontaneous abortions occur in about $30 \%$ of pregnancies after induction of ovulation in women with the syndrome regardless of the treatment used. Because polycystic ovaries are also found in women who ovulate ${ }^{23}$ we investigated a possible association between polycystic ovaries and recurrent miscarriages in women with spontaneous ovulatory cycles. As defects in the luteal phase, which may occur in women with polycystic ovaries, may be related to miscarriage we also assessed progesterone secretion.

\section{Subjects, methods, and results}

We studied 56 consecutive patients presenting to the recurrent miscarriage clinic; all ovulated spontaneously. We recorded their menstrual histories, their heights and weights, and whether they had acne or hirsutism. Ultrasonography of the pelvis was performed, and polycystic ovaries were identified. ${ }^{2}$ Blood was taken for measurement of luteinising hormone concentration. A control group of 11 parous volunteers with no history of disturbance of their ovulatory cycles or recurrent miscarriages were examined similarly. Early morning urine specimens were collected daily throughout an ovulatory cycle from 30 women who had had recurrent miscarriages, and the concentration of pregnanediol- $3 \alpha$-glucuronide, the major urinary metabolite of progesterone, was measured. Values were compared with those obtained in five controls and in 20 cycles in nine normal, non-parous women (table).

Forty six $(82 \%)$ of the 56 women who had had recurrent miscarriages, had polycystic ovaries compared with two (18\%) of the 11 parous women $\left(\chi^{2}=15.5, p<0.001\right)$. Age, body mass index, and length of the ovulatory cycle were not significantly different among all the groups of women. Six of the 46 patients with recurrent miscarriages and polycystic ovaries had mild or moderate hirsutism and 13 had acne, whereas only one of the 10 women with recurrent miscarriages and normal ovaries had hirsutism (and acne). ${ }^{2}$ None of the parous control women was hirsute or had acne. The serum luteinising hormone and midluteal pregnanediol-3 $\alpha$-glucuronide concentrations were normal in all of the women with recurrent miscarriages.

Median (range) values for clinical features and hormone concentrations in women with recurrent miscarriages and controls

\begin{tabular}{|c|c|c|c|c|}
\hline \multirow{2}{*}{. } & \multicolumn{2}{|c|}{ Women with recurrent miscarriage } & \multicolumn{2}{|c|}{ Controls } \\
\hline & $\begin{array}{l}\text { Normal ovaries } \\
\quad(n=10)\end{array}$ & $\begin{array}{l}\text { Polycystic ovaries } \\
\qquad(n=46)\end{array}$ & $\begin{array}{l}\text { Parous } \\
\left(n=11^{\star}\right)\end{array}$ & $\begin{array}{c}\text { Non-parous } \\
(n=20 \dagger)\end{array}$ \\
\hline $\begin{array}{l}\text { Length of menstrual cycle (days) } \\
\text { Body mass index }\left(\mathrm{kg} / \mathrm{m}^{2}\right) \\
\text { Luteinising hormone }(\mathrm{IU} / \mathrm{l}) \text { (normal range } 0 \cdot 8-11 \cdot 5) \\
\text { Pregnanediol-3 } \alpha \text {-glucuronide } \$(\mu \mathrm{mol} / \mathrm{l})\end{array}$ & $\begin{array}{l}28(26-32) \\
21(19-24) \\
4 \cdot 9(2 \cdot 8-7 \cdot 0) \\
16 \cdot 5(5 \cdot 9-29 \cdot 0)\end{array}$ & $\begin{array}{l}30(21-57) \\
22(18-42) \\
5 \cdot 9(1 \cdot 7-11 \cdot 1) \\
15 \cdot 6(5 \cdot 0-69 \cdot 2)\end{array}$ & $\begin{array}{l}29(26-33) \\
23(20-25) \\
4 \cdot 3(2 \cdot 1-6 \cdot 9) \\
18 \cdot 7(16 \cdot 5-35 \cdot 6)\end{array}$ & $16 \cdot 8(4 \cdot 1-21 \cdot 8)$ \\
\hline
\end{tabular}

$\star$ Except for measurements of pregnanediol-3 $\alpha$-glucuronide, where $\mathrm{n}=5$.

tTwenty cycles in nine controls.

Excluding measurements obtained in mid-cycle-that is, in presence of follicle $\geqslant 16 \mathrm{~mm}$ in diameter.

†Derived from average of three mid-luteal measurements in each subject.

.

